\title{
Co-deficiency of B7-H3 and B7-H4 identifies high CD8 + T cell infiltration and better prognosis in pancreatic cancer
}

\author{
Shuping Si, Lei Wang, Hui Cao, Yuhua Xu and Qiang Zhan*
}

\begin{abstract}
Background: Immunotherapy is a novel hotspot for the treatment of pancreatic adenocarcinoma (PAAD). However, potential biomarkers which could identify the inflamed tumor microenvironment (TME) are urgently required.

Methods: In the present study, we measured the levels of B7-H3, B7-H4, and major tumor-infiltrating immune cells (TIICS) using bioinformatics analyses and immunohistochemistry (IHC) staining on PAAD samples represented in the tissue microarray (TMA) format. Statistical analysis and figures exhibition were performed using R 4.1.0, SPSS 26.0, and GraphPad Prism 6.0.

Results: $\mathrm{B} 7-\mathrm{H} 3$ and $\mathrm{B} 7-\mathrm{H} 4$ were up-regulated in PAAD compared with para-tumor tissues, and their expression exhibited no tight correlation in PAAD tissues. B7-H3 and B7-H4 were lowly expressed in well-differentiated PAAD tissues and correlated with poorly differentiated grades. Besides, single $\mathrm{B} 7-\mathrm{H} 3$ or $\mathrm{B} 7-\mathrm{H} 4$ expression exhibited limited prognostic value, but co-deficiency of B7-H3 and B7-H4 predicted a better prognosis in PAAD. Moreover, co-deficiency of B7-H3 and B7-H4 indicated immuno-hot tumors with high CD8 + T cell infiltration.
\end{abstract}

Conclusions: Overall, combined $\mathrm{B} 7-\mathrm{H} 3$ and $\mathrm{B} 7-\mathrm{H} 4$ expression is a promising stratification strategy to assess prognosis and immunogenicity in PAAD, which could be used as a novel classifier in clinical practice.

Keywords: B7-H3, B7-H4, prognosis, Immune cell infiltration, pancreatic cancer

\section{Background}

Pancreatic adenocarcinoma (PAAD) is one of the most fatal malignant tumors in the world, featured with dreadful invasiveness, powerful proliferative potential, and poor clinical outcome. The early diagnosis of PAAD is rare on account of the obscure symptoms, and the morbidity of PAAD has been significantly elevated over the last few decades. Although PAAD does not account for a high proportion of all patients, survival is lowest for cancers of the pancreas (10\%) [1]. With the rapid progress of emerging therapeutic programs, immunotherapy is

\footnotetext{
*Correspondence: ryzhanqiang@163.com

Department of Gastroenterology, Wuxi People's Hospital Affiliated

to Nanjing Medical University, No. 299 Qing Yang Road, Wuxi 214023, China
}

becoming a promising hotspot for the treatment of PAAD [2]. It has been revealed that the response for immunotherapy is low in PAAD due to its non-inflamed tumor microenvironment (TME) [3-5]. Growing evidence indicates that tumor progression and therapeutic response were critically affected by host immune response, which depends on the abundance of tumor-infiltrating immune cells (TIICs) in TME $[6,7]$. Thus, potential biomarkers which could identify the abundance of TIICs in TME of PAAD are urgently required in clinical practice.

In recent years, the roles of co-stimulatory B7 family molecules in regulating tumor immunity have been widely concerned, specially programmed cell death ligand 1 (PD-L1), also named as B7-H1 [8]. PD-L1 expression is usually correlated with inflamed TME phenotype 
and predicts a high response rate to immunotherapy in the clinic $[9,10]$. In addition to $\mathrm{B} 7-\mathrm{H} 1, \mathrm{~B} 7-\mathrm{H} 3$ and $\mathrm{B} 7-\mathrm{H} 4$ are becoming promising hotspots [11]. According to previous reports, $\mathrm{B} 7-\mathrm{H} 3$ and $\mathrm{B} 7-\mathrm{H} 4$ are significantly upregulated in PAAD tissues compared with non-tumor or normal pancreas tissues [12, 13]. Besides, co-expressed or mutually-exclusive patterns of B7 molecules predict inflamed or non-inflamed TME in multiple human cancers $[14,15]$. However, the correlation between B7-H3 and $\mathrm{B} 7-\mathrm{H} 4$ expression and TIICs abundance as well as the predictive value of combined $\mathrm{B} 7-\mathrm{H} 3$ and $\mathrm{B} 7-\mathrm{H} 4$ in assessing prognosis has not been investigated yet.

In this research, we first analyzed the expression of B7-H3 and B7-H4 as well as their associations between clinic-pathological features in PAAD. Besides, the prognostic values and immuno-correlations of B7-H3, B7-H4, and combined expression were also evaluated. As result, we found that $\mathrm{B} 7-\mathrm{H} 3$ and $\mathrm{B} 7-\mathrm{H} 4$ were upregulated in PAAD tissues and correlated with advanced differentiated grades. Moreover, co-deficiency of $\mathrm{B} 7-\mathrm{H} 3$ and B7-H4 in PAAD predicted better clinical outcomes and identifies high CD8 $+\mathrm{T}$ cell infiltration. Overall, co-deficiency of $\mathrm{B} 7-\mathrm{H} 3$ and $\mathrm{B} 7-\mathrm{H} 4$ is a promising prognostic and immunogenic biomarker in PAAD.

\section{Methods}

\section{Acquisition of TCGA data}

Normalized RNA-sequencing (RNA-seq) data and corresponding clinical information of PAAD samples in the Cancer Genome Atlas (TCGA) database were downloaded from the UCSC Xena website (https://xenab rowser.net/datapages/). Patients with missing or insufficient data were excluded from this research. Finally, a total of 178 tumor samples were retained for further analysis.

\section{Analyses of the GEPIA and CPTAC databases}

GEPIA (http://gepia.cancer-pku.cn/) was an interactive website based on the TCGA and GTEx databases and used for RNA expression analyses [16]. In the present study, the GEPIA website was used to explore the expression levels of B7-H3 and B7-H4 in PAAD and adjacent pancreas tissues. In addition, to further compare the differential expressions of $\mathrm{B} 7-\mathrm{H} 3$ and $\mathrm{B} 7-\mathrm{H} 4$ at protein levels, the proteome data of the CPTAC dataset (http:// ualcan.path.uab.edu/analysis-prot.html) were also used for differential analyses of B7-H3 and B7-H4 [17].

\section{Immune infiltration analysis}

Tumor Immune Estimation Resource (TIMER) database is an online tool for systematic analysis of immune cell infiltration across diverse cancer types from TCGA [18]. We evaluated the correlation of B7-H3 \& B7-H4 expressions with the infiltration of main types of immune cells, including B cells, CD8 + T cells, CD4 + T cells, neutrophils, macrophages, and dendritic cells (DCs).

The relative abundance of more types of infiltrating immune cells was analyzed using the xCell algorithm (https://xcell.ucsf.edu/), an emerging tool to estimate the abundance of 64 immune and stromal cell types based on gene expression profiles [19]. Pre-calculated infiltrating data of TIICs corresponding to TCGA-PAAD samples were downloaded from the xCell website.

\section{Clinical samples}

The PAAD tissue microarray (TMA, Cat. no HPanA150CS04) was purchased from Outdo BioTech (Shanghai, China). A total of 120 PAAD and 30 paired para-tumor tissues were included in the TMA. Detailed clinic-pathological characteristics of these patients were also provided by Outdo BioTech. Ethical approval for the use of the TMA was granted by the Clinical Research Ethics Committee (Outdo BioTech).

\section{Immunohistochemistry}

Immunohistochemistry (IHC) staining was performed on the TMA of PAAD tissues. The primary antibodies used in the research were as follows: anti-B7-H3 (1:8000 dilution, Cat. no ab219648, Abcam, Cambridge, UK), anti-B7-H4 (1:50 dilution, Cat. no ab252438, Abcam, Cambridge, UK), and anti-CD8 (Ready-to-use, Cat. no PA067, Abcarta, Suzhou, China). Antibody staining was visualized using diaminobenzidine (DAB) and hematoxylin counterstain, and stained TMA was scanned using Aperio Digital Pathology Slide Scanners.

\section{Semi-quantitative assessment}

A total of 104 TMA points were retained for further analysis after the exfoliated points were removed. All stained points were independently assessed by two senior pathologists. For semi-quantitative evaluation of B7-H3 and $\mathrm{B} 7-\mathrm{H} 4$ staining, the percentage of positively stained tumor cells was scored as 0-4: $0(<1 \%), 1(1-5 \%), 2$ (6-25\%), $3(26-50 \%)$ and $4(>50 \%)$. The staining intensity was scored as 0-3: 0 (negative), 1 (weak), 2 (moderate) and 3 (strong). The immune-reactivity score (IRS) equals the percentages of positive cells multiplied with staining intensity. For semi-quantitative evaluation of CD8 staining, the infiltration level of CD8 + immune cells was evaluated by estimating the percentage of cells with strong intensity of membrane staining in the stroma cells [20].

\section{Statistical analysis}

Statistical analysis and figures exhibition were performed using R 4.1.0, SPSS 26.0, and GraphPad Prism 6.0. Most of the data were analyzed by Student's t-test, 


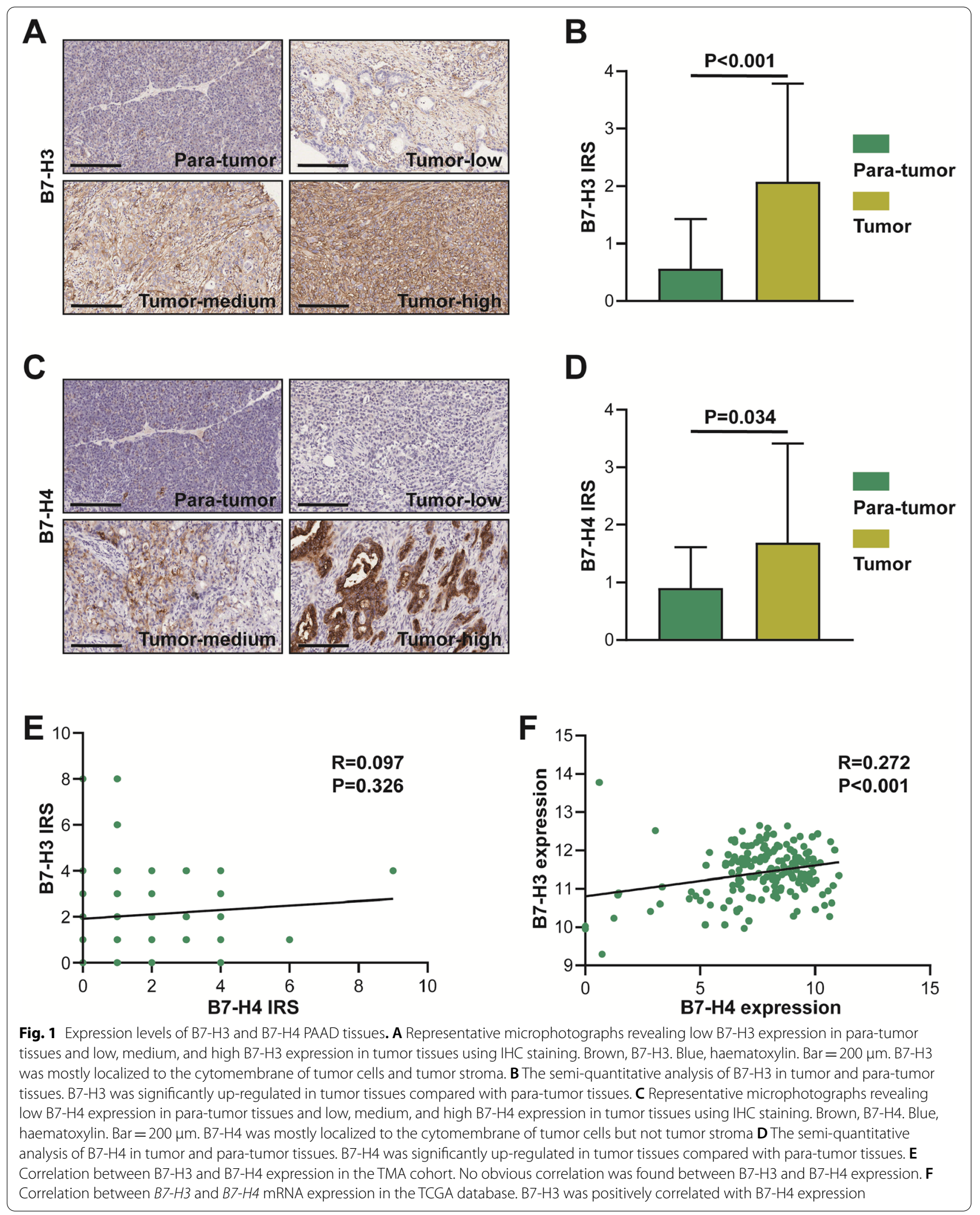


Table 1 Association between B7-H3 \& B7-H4 expression and clinic-pathological parameters in PAAD

\begin{tabular}{|c|c|c|c|c|c|c|c|c|c|}
\hline \multirow{2}{*}{$\begin{array}{l}\text { Clinic-pathological } \\
\text { parameters }\end{array}$} & \multirow[t]{2}{*}{ Cases } & \multicolumn{2}{|c|}{ B7-H3 expression } & \multirow[t]{2}{*}{$x^{2}$ value } & \multirow[t]{2}{*}{$P$ value } & \multicolumn{2}{|c|}{ B7-H4 expression } & \multirow[t]{2}{*}{$\mathrm{x}^{2}$ value } & \multirow[t]{2}{*}{$P$ value } \\
\hline & & Low & High & & & Low & High & & \\
\hline \multicolumn{10}{|l|}{ Gender } \\
\hline Female & 46 & 24 & 22 & 0.156 & 0.693 & 24 & 22 & 0.698 & 0.404 \\
\hline Male & 58 & 28 & 30 & & & 35 & 23 & & \\
\hline \multicolumn{10}{|l|}{ Age } \\
\hline$\leq 60$ & 47 & 25 & 22 & 0.349 & 0.554 & 22 & 25 & 3.439 & 0.064 \\
\hline$>60$ & 57 & 27 & 30 & & & 37 & 20 & & \\
\hline \multicolumn{10}{|l|}{ Differentiation } \\
\hline Well & 65 & 39 & 26 & 5.455 & 0.020 & 42 & 23 & 6.292 & 0.012 \\
\hline Moderate \& poor & 34 & 12 & 22 & & & 13 & 21 & & \\
\hline \multicolumn{10}{|l|}{ T stage } \\
\hline $\mathrm{T} 1-2$ & 29 & 17 & 12 & 0.829 & 0.363 & 19 & 10 & 1.466 & 0.226 \\
\hline T3-4 & 56 & 27 & 29 & & & 29 & 27 & & \\
\hline \multicolumn{10}{|l|}{ N stage } \\
\hline No & 48 & 25 & 23 & 0.157 & 0.692 & 28 & 20 & 0.009 & 0.925 \\
\hline N1 & 54 & 26 & 28 & & & 31 & 23 & & \\
\hline \multicolumn{10}{|l|}{ M stage } \\
\hline MO & 98 & 51 & 47 & / & $0.205^{*}$ & 58 & 40 & / & $0.083^{*}$ \\
\hline M1 & 6 & 1 & 5 & & & 1 & 5 & & \\
\hline \multicolumn{10}{|l|}{ Clinical stage } \\
\hline $1-2 \mathrm{~A}$ & 46 & 25 & 21 & 0.624 & 0.430 & 27 & 19 & 0.130 & 0.719 \\
\hline $2 B-4$ & 58 & 27 & 31 & & & 32 & 26 & & \\
\hline
\end{tabular}

Note: $* P$ value was calculated by Fisher test

Mann-Whitney test, and one-way ANOVA. KaplanMeier survival plots were generated with survival curves compared by log-rank test. The Chi-square test was used to assess differences in clinic-pathological features between groups with different risks. For all analyses, differences were deemed statistically significant when $\mathrm{P}$-value was less than or equal 0.05 .

\section{Results}

\section{B7-H3 and B7-H4 are up-regulated in PAAD compared} with para-tumor tissues

As described previously, several research groups reported that $\mathrm{B} 7-\mathrm{H} 3$ and $\mathrm{B} 7-\mathrm{H} 4$ are up-regulated in multiple cancers $[21,22]$. In the GEPIA and CPTAC databases, B7-H3 was upregulated in PAAD tissues, while B7-H4 showed no difference between tumor and paratumor tissues (Figure S1A-D). We also assessed B7-H3 and B7-H4 expression based on IHC staining. As shown in Fig. 1A, the immuno-reactivity of B7-H3 was mostly localized to the cytomembrane of tumor cells and tumor stroma. After the semi-quantitative analysis, we found that the IRS of B7-H3 in PAAD tissues was significantly higher than para-cancerous tissues (Fig. 1B). Similar to B7-H3, the immuno-reactivity of B7-H4 was also localized to the cytomembrane of tumor cells and but not stroma (Fig. 1C). Besides, the expression of B7-H4 was notably up-regulated in PAAD tissues compared with para-cancerous tissues (Fig. 1D). We also evaluated the correlation between B7-H3 and B7-H4 expression, and the results showed that the protein expression of $\mathrm{B} 7-\mathrm{H} 3$ and B7-H4 had no obvious correlation (Fig. 1E). However, in the TCGA database, B7-H3 mRNA was positively correlated with B7-H4 mRNA (Fig. 1F). Overall, these data suggest that the expression of $\mathrm{B} 7-\mathrm{H} 3$ and $\mathrm{B} 7-\mathrm{H} 4$ proteins are up-regulated in PAAD tissues and have no notable correlation.

\section{B7-H3 and B7-H4 are lowly expressed in well-differentiated PAAD tissues}

Next, the associations between clinic-pathological features and B7 molecules expression were evaluated in the current patients' cohort. As shown in Table 1, the expression levels of B7-H3 and B7-H4 were not associated with gender, age, $\mathrm{T}$ stage, $\mathrm{N}$ stage, $\mathrm{M}$ stage, and clinical stage. However, these two B7 molecules were significantly associated with differentiation (Table 1). We next compared the expression levels of B7-H3 and B7-H4 in well-differentiated and moderate \& poordifferentiated groups, and the results exhibited that B7-H3 and B7-H4 were notably downregulated in 


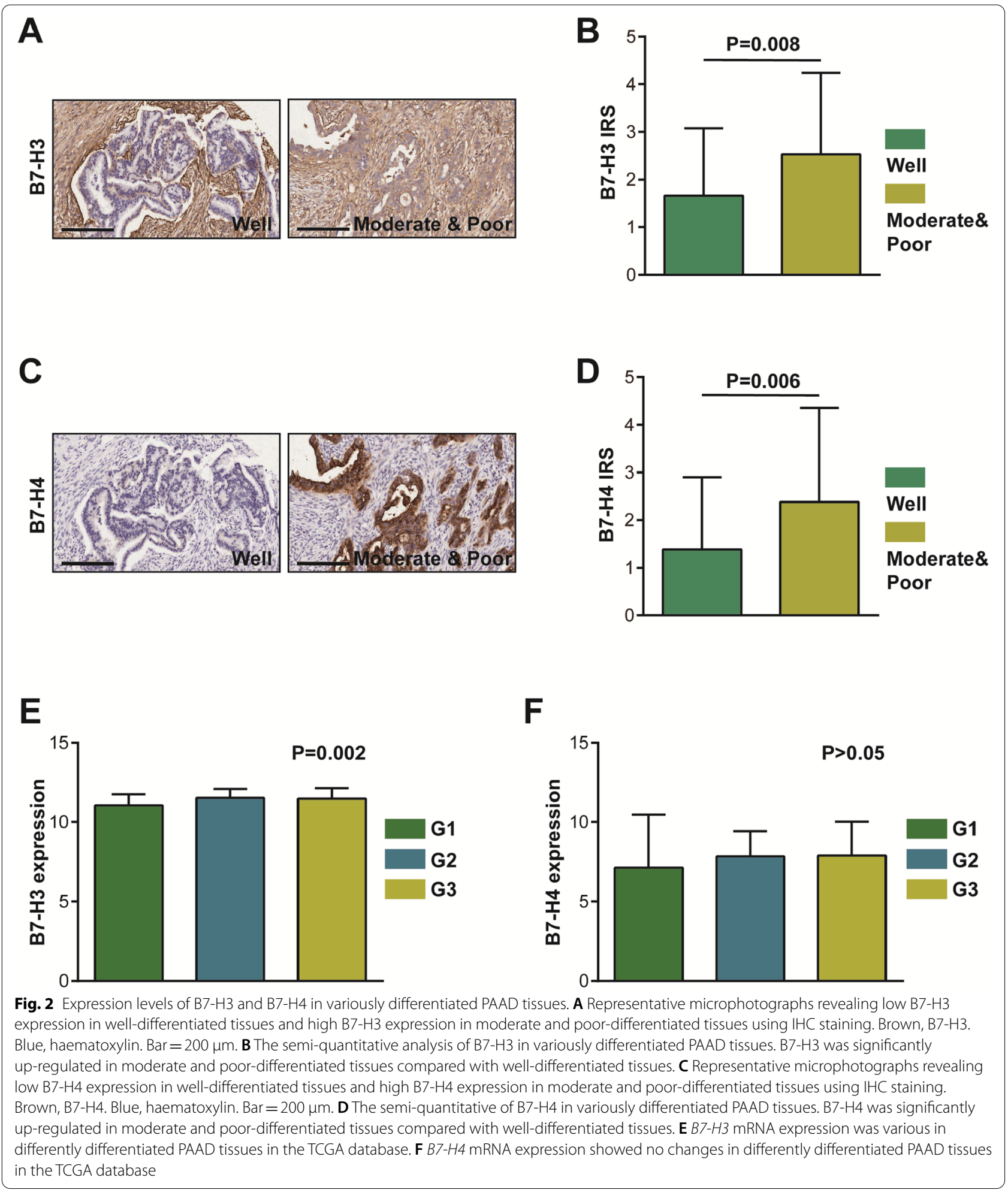

well-differentiated PAAD tissues (Fig. 2A-D). Besides, in the TCGA database, B7-H3 was significantly correlated with advanced differentiated grades (Fig. 2E). Although B7-H4 tended to be upregulated with advanced differentiated grades, the difference was not statistically significant (Fig. 2F). Overall, deficiency of B7-H3 and/or B7-H4 identifies well-differentiated tumors in PAAD. 


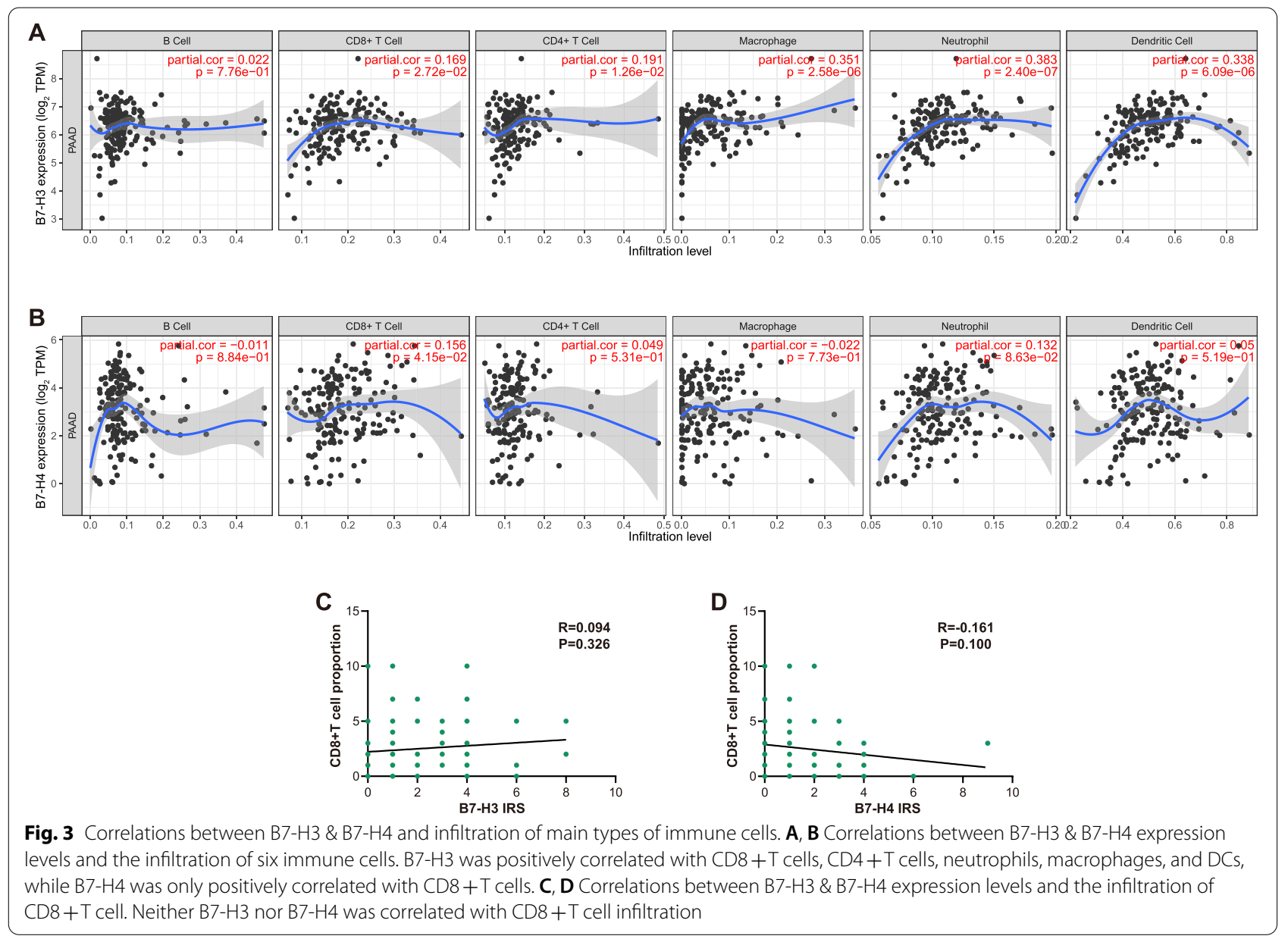

\section{Correlations between B7-H3 \& B7-H4 and infiltration of main types of immune cells}

Given B7-H3 \& B7-H4 were correlated with TIICs in other cancers [23, 24], we also assessed the correlations between $\mathrm{B} 7-\mathrm{H} 3$ \& $\mathrm{B} 7-\mathrm{H} 4$ and infiltration of main types of immune cells. B7-H3 was positively correlated with CD8 + T cells, CD4 + T cells, neutrophils, macrophages, and DCs, while B7-H4 was only positively correlated with $\mathrm{CD} 8+\mathrm{T}$ cells (Fig. 3A-B). To validate the results, we performed IHC staining using anti-CD8 antibody. However, neither B7-H3 nor B7-H4 was correlated with $\mathrm{CD} 8+\mathrm{T}$ cell infiltration (Fig. 3C-D). Thus, the correlations between B7-H3 \& B7-H4 and immune cells infiltration are contradictory and need to be further confirmed.

\section{Co-deficiency of B7-H3 and B7-H4 predicts a better prognosis}

We further definite the prognostic values of these two B7 molecules in patients with PAAD. Patients in the TCGA cohort were divided into low $(n=89)$ and high $(n=89)$ groups at the cut-off value of the median expression. The Kaplan-Meier curves exhibited B7-H3 and B7-H4 could not effectively predict overall survival (OS) in patients with PAAD (Fig. 4A, C). In term of progressionfree survival (PFS), patients with high B7-H3 expression had a significantly worse prognosis than those with low expression (Fig. 4B). However, B7-H4 could not effectively predict PFS in PAAD patients (Fig. 4D). Furthermore, combined B7-H3 and B7-H4 expression was a promising prognostic biomarker. Co-deficiency of B7-H3 and $\mathrm{B} 7-\mathrm{H} 4$ predicted better prognosis in terms of both OS and PFS (Fig. 4E-F) in PAAD. Taken together, these results indicated that co-deficiency of B7-H3 and B7-H4 was a favorable prognostic factor in PAAD patients.

\section{Co-deficiency of B7-H3 and B7-H4 indicates high CD8 + T cell infiltration}

Given co-expressed or mutually-exclusive patterns of B7 molecules predict inflamed or non-inflamed TME in multiple human cancers $[14,15]$, we next assess whether co-deficiency of $\mathrm{B} 7-\mathrm{H} 3$ and $\mathrm{B} 7-\mathrm{H} 4$ predicted specific TME features. The $x$ Cell tool was used to estimate the abundance of 64 immune and stromal cell types in the TCGA database, and the abundance of these cells in the 


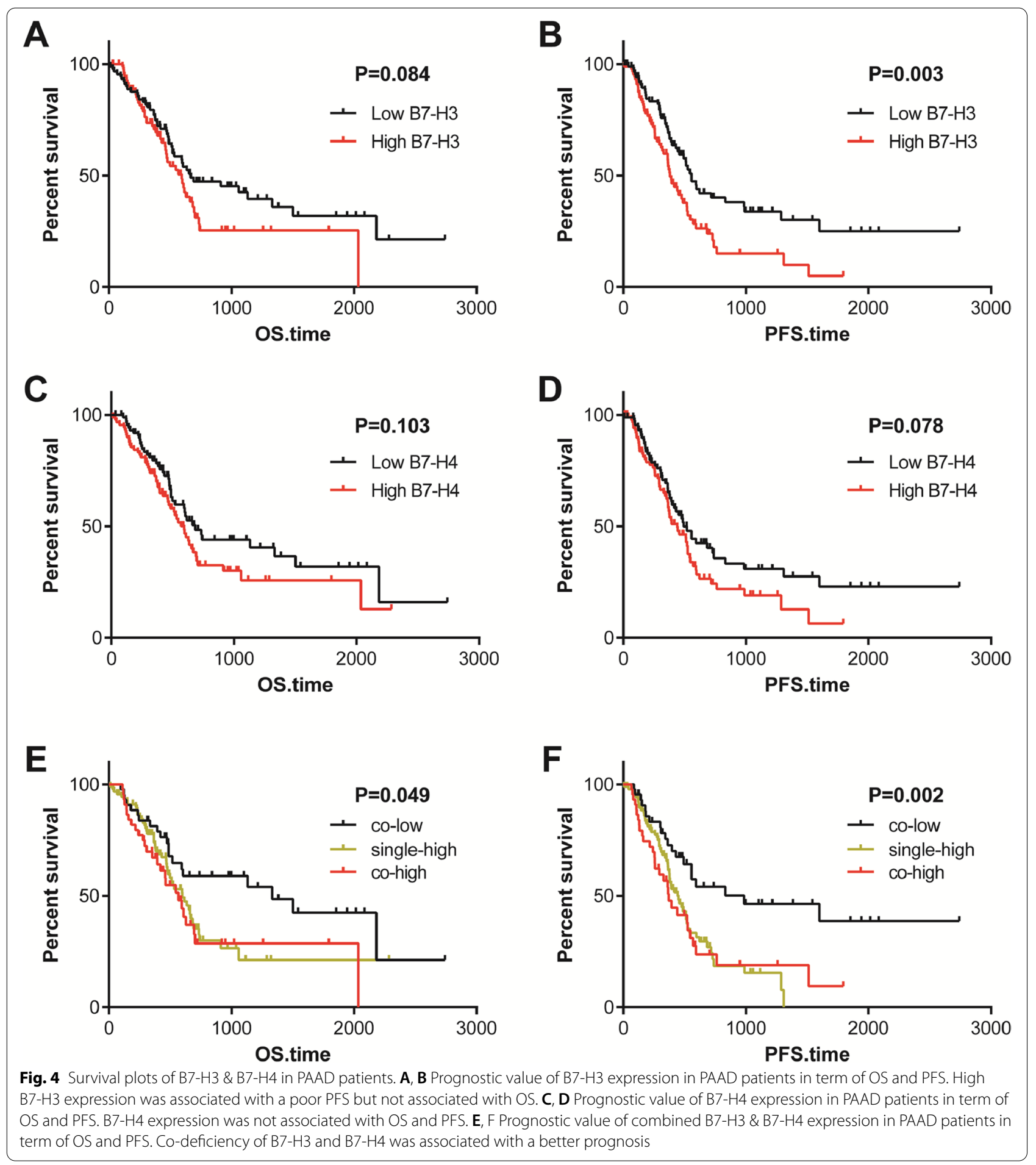

co-low, single-high and co-high groups were next compared. A subset of non-tumor cells was different in the three groups, and total CD8 $+\mathrm{T}$ cells and $\mathrm{CD} 8+\mathrm{Tcm}$ cells were increased in the co-low groups (Table 2, Fig. 5A-B). As expected, the infiltrating abundance of
$\mathrm{CD} 8+\mathrm{T}$ cell was highest in the co-low group among these three groups (Fig. 5C-D). Overall, co-deficiency of B7-H3 and B7-H4 predicts high CD8 + T cell infiltration, which may explain the better prognosis in the co-low group of PAAD patients. 
Table 2 Differences of immune cells levels estimated by xCell algorithm

\begin{tabular}{|c|c|c|c|c|c|}
\hline \multirow[t]{2}{*}{ Immune cells } & \multicolumn{3}{|c|}{ Average } & \multirow[t]{2}{*}{$F$ value } & \multirow[t]{2}{*}{$P$ value } \\
\hline & co-low & single-high & co-high & & \\
\hline $\mathrm{aDC}$ & 0.080 & 0.108 & 0.097 & 2.582 & 0.079 \\
\hline Adipocytes & 0.108 & 0.076 & 0.031 & 3.456 & 0.034 \\
\hline Astrocytes & 0.040 & 0.087 & 0.106 & 13.338 & 0.000 \\
\hline B cells & 0.108 & 0.111 & 0.062 & 0.538 & 0.585 \\
\hline Basophils & 0.038 & 0.012 & 0.007 & 6.142 & 0.003 \\
\hline CD4 + memory T cells & 0.137 & 0.125 & 0.107 & 1.028 & 0.360 \\
\hline CD4 + naïve T cells & 0.060 & 0.064 & 0.045 & 0.577 & 0.563 \\
\hline CD4 $+\mathrm{T}$ cells & 0.004 & 0.002 & 0.000 & 0.622 & 0.538 \\
\hline $\mathrm{CD} 4+\mathrm{Tcm}$ & 0.006 & 0.004 & 0.003 & 2.194 & 0.115 \\
\hline CD4+Tem & 0.014 & 0.011 & 0.011 & 0.850 & 0.429 \\
\hline CD8 + naïve T cells & 0.008 & 0.009 & 0.007 & 1.943 & 0.146 \\
\hline CD8 + T cells & 0.034 & 0.015 & 0.011 & 10.264 & 0.000 \\
\hline $\mathrm{CD} 8+\mathrm{Tcm}$ & 0.022 & 0.014 & 0.010 & 3.071 & 0.049 \\
\hline CD8+Tem & 0.003 & 0.002 & 0.000 & 2.196 & 0.114 \\
\hline $\mathrm{cDC}$ & 0.026 & 0.022 & 0.019 & 0.701 & 0.498 \\
\hline Chondrocytes & 0.126 & 0.161 & 0.163 & 4.418 & 0.013 \\
\hline Class switched memory B cells & 0.034 & 0.025 & 0.020 & 1.493 & 0.228 \\
\hline CLP & 0.048 & 0.042 & 0.044 & 1.146 & 0.320 \\
\hline CMP & 0.000 & 0.000 & 0.000 & 1.071 & 0.345 \\
\hline DC & 0.060 & 0.071 & 0.056 & 1.160 & 0.316 \\
\hline Endothelial cells & 0.142 & 0.143 & 0.145 & 0.010 & 0.990 \\
\hline Eosinophils & 0.030 & 0.036 & 0.038 & 3.502 & 0.032 \\
\hline Epithelial cells & 0.726 & 0.891 & 0.918 & 7.364 & 0.001 \\
\hline Erythrocytes & 0.000 & 0.000 & 0.000 & 0.943 & 0.391 \\
\hline Fibroblasts & 0.121 & 0.138 & 0.137 & 0.559 & 0.573 \\
\hline GMP & 0.004 & 0.002 & 0.000 & 2.493 & 0.086 \\
\hline Hepatocytes & 0.085 & 0.090 & 0.098 & 0.516 & 0.598 \\
\hline $\mathrm{HSC}$ & 0.196 & 0.221 & 0.215 & 1.009 & 0.367 \\
\hline $\mathrm{iDC}$ & 0.119 & 0.131 & 0.114 & 0.591 & 0.555 \\
\hline Keratinocytes & 0.092 & 0.137 & 0.142 & 5.336 & 0.006 \\
\hline Ly Endothelial cells & 0.154 & 0.157 & 0.154 & 0.016 & 0.984 \\
\hline Macrophages & 0.054 & 0.074 & 0.072 & 2.933 & 0.056 \\
\hline Macrophages M1 & 0.046 & 0.065 & 0.065 & 5.435 & 0.005 \\
\hline Macrophages M2 & 0.015 & 0.017 & 0.013 & 1.055 & 0.350 \\
\hline Mast cells & 0.032 & 0.029 & 0.024 & 3.281 & 0.040 \\
\hline Megakaryocytes & 0.014 & 0.014 & 0.012 & 1.286 & 0.279 \\
\hline Melanocytes & 0.013 & 0.012 & 0.011 & 0.447 & 0.640 \\
\hline Memory B cells & 0.015 & 0.016 & 0.009 & 0.305 & 0.738 \\
\hline MEP & 0.035 & 0.030 & 0.027 & 1.792 & 0.170 \\
\hline Mesangial cells & 0.081 & 0.093 & 0.106 & 8.969 & 0.000 \\
\hline Monocytes & 0.021 & 0.033 & 0.021 & 2.337 & 0.100 \\
\hline MPP & 0.000 & 0.000 & 0.000 & 0.056 & 0.945 \\
\hline MSC & 0.140 & 0.265 & 0.310 & 28.875 & 0.000 \\
\hline Mv Endothelial cells & 0.052 & 0.057 & 0.059 & 0.483 & 0.618 \\
\hline Myocytes & 0.006 & 0.005 & 0.004 & 1.011 & 0.366 \\
\hline Naïve B cells & 0.010 & 0.013 & 0.007 & 0.398 & 0.672 \\
\hline Neurons & 0.066 & 0.015 & 0.014 & 17.406 & 0.000 \\
\hline Neutrophils & 0.001 & 0.001 & 0.001 & 0.094 & 0.910 \\
\hline
\end{tabular}


Table 2 (continued)

\begin{tabular}{|c|c|c|c|c|c|}
\hline \multirow[t]{2}{*}{ Immune cells } & \multicolumn{3}{|c|}{ Average } & \multirow[t]{2}{*}{$F$ value } & \multirow[t]{2}{*}{$P$ value } \\
\hline & co-low & single-high & co-high & & \\
\hline NK cells & 0.000 & 0.000 & 0.000 & 0.458 & 0.633 \\
\hline NKT & 0.024 & 0.022 & 0.026 & 0.959 & 0.385 \\
\hline Osteoblast & 0.077 & 0.036 & 0.034 & 10.543 & 0.000 \\
\hline $\mathrm{pDC}$ & 0.072 & 0.058 & 0.046 & 1.981 & 0.141 \\
\hline Pericytes & 0.074 & 0.099 & 0.115 & 3.779 & 0.025 \\
\hline Plasma cells & 0.011 & 0.008 & 0.005 & 6.987 & 0.001 \\
\hline Platelets & 0.001 & 0.000 & 0.000 & 7.379 & 0.001 \\
\hline Preadipocytes & 0.009 & 0.002 & 0.001 & 3.916 & 0.022 \\
\hline Pro B cells & 0.002 & 0.002 & 0.001 & 0.319 & 0.727 \\
\hline Sebocytes & 0.408 & 0.533 & 0.534 & 4.005 & 0.020 \\
\hline Skeletal muscle & 0.000 & 0.000 & 0.000 & 2.332 & 0.100 \\
\hline Smooth muscle & 0.386 & 0.332 & 0.333 & 12.517 & 0.000 \\
\hline Tgd cells & 0.000 & 0.000 & 0.000 & 0.263 & 0.769 \\
\hline Th1 cells & 0.058 & 0.046 & 0.047 & 1.671 & 0.191 \\
\hline Th2 cells & 0.009 & 0.010 & 0.009 & 0.041 & 0.960 \\
\hline Tregs & 0.016 & 0.011 & 0.009 & 3.210 & 0.043 \\
\hline
\end{tabular}

Abbreviations: $a D C$ Activated dendritic cells, CD4 +Tcm, CD4 + central memory T-cells, CD4 + Tem CD4 + effector memory T-cells, CD8 + Tcm CD8 + central memory T-cells, CD8 + Tem CD8 + effector memory T-cells, CDC Xonventional dendritic cells, CLP Common lymphoid progenitors, CMP Common myeloid progenitors, DC Dendritic cells, GMP Granulocyte-macrophage progenitors, HSC Hematopoietic stem cells, iDC Immature dendritic cells, ly endothelial cells Lymphatic endothelial cells, MEP Megakaryocyte-erythroid progenitors, MPP Multipotent rogenitors, MSC Mesenchymal stem cells, mv endothelial cells Microvascular endothelial cells, NKT Natural killer T-cells, pDC Plasmacytoid dendritic cells, Tgd cells Gamma delta T-cells, Th1 cells Type 1 T-helper cells, Th2 cells Type 2 T-helper cells, Tregs Regulatory T-cells

\section{Discussion}

It has been proved that increased CD8 $+\mathrm{T}$ cell infiltration is one of the notable features of immuno-hot tumors, which indicates a better prognosis and high therapeutic response [25-27]. Thus, reliable biomarkers for the identification of immuno-hot tumors in PAAD are urgent in clinical practice. In the current research, we analyzed the expression patterns of $\mathrm{B} 7-\mathrm{H} 3$ and $\mathrm{B} 7-\mathrm{H} 4$ in PAAD and combined their expression as a novel stratification strategy. We found that B7-H3 and B7-H4 were highly expressed in PAAD tissues and higher in poorly differentiated tumors. Moreover, co-deficiency of B7-H3 and $\mathrm{B} 7-\mathrm{H} 4$ indicates a better prognosis and high $\mathrm{CD} 8+\mathrm{T}$ cell infiltration.

B7-H3 is a negative regulator and inhibits T cell proliferation and cytokine production mediated by antibody to CD3 [28]. In cancers, B7-H3 acts as an inhibitory immune checkpoint that negatively regulates anti-tumor immunity. Overexpression of B7-H3 in tumor tissues is a poor prognostic biomarker in prostate cancer [29], upper tract urothelial carcinoma [30], small cell lung cancer [31], etc. Besides, inhibition of B7-H3 expression is a promising therapeutic strategy for human cancer. In previous research, B7-H3 targeted therapies have been mentioned, which shows promising applications, including monoclonal antibodies against B7-H3, specific antibody-dependent cell-mediated cytotoxicity, antibody drug conjugates, specific small-molecule inhibitor, and chimeric antigen receptor T-cell therapy [21]. B7-H3 expression shows no notable correlation with major TIICs, including CD3+, CD8 + and CD20 + TIICs in small cell lung cancer [32], whereas B7-H3 expression is positively correlated with the abundance of CD45 + and CD8 + TIICs in non-smallcell lung cancer [33]. In PAAD, B7-H3 was overexpressed and promoted tumor progression [34]. In addition, tumor high B7-H3 expression was independently associated with poor survival [35]. In our research, B7-H3 was positively correlated with $\mathrm{CD} 8+\mathrm{T}$ cells, $\mathrm{CD} 4+\mathrm{T}$ cells, neutrophils, macrophages, and DCs estimated by TIMER algorithm, but $\mathrm{B} 7-\mathrm{H} 3$ expression was not correlated with the abundance of CD8 + TIICs in our validated cohort. The contradictory results need to be further confirmed.

Similar to B7-H3, B7-H4 is also an inhibitory immune checkpoint and predicts poor prognosis in multiple human cancers [36-38]. Besides, immunotherapy targeting $\mathrm{B} 7-\mathrm{H} 4$ is under pre-clinical investigation [22]. For example, pharmacologic inhibition of B7-H4 glycosylation restores anti-tumor immunity in immunocold breast cancer [39]. It has been reported that B7-H4 expression is inversely correlated with $\mathrm{T}$ cell infiltration in clear cell ovarian cancer [40] and breast cancer [24]. In PAAD, B7-H4 promoted cancer progression and inhibited apoptosis in PAAD cells [41]. In addition, a metaanalysis revealed that high expression of $\mathrm{B} 7-\mathrm{H} 4$ was an 


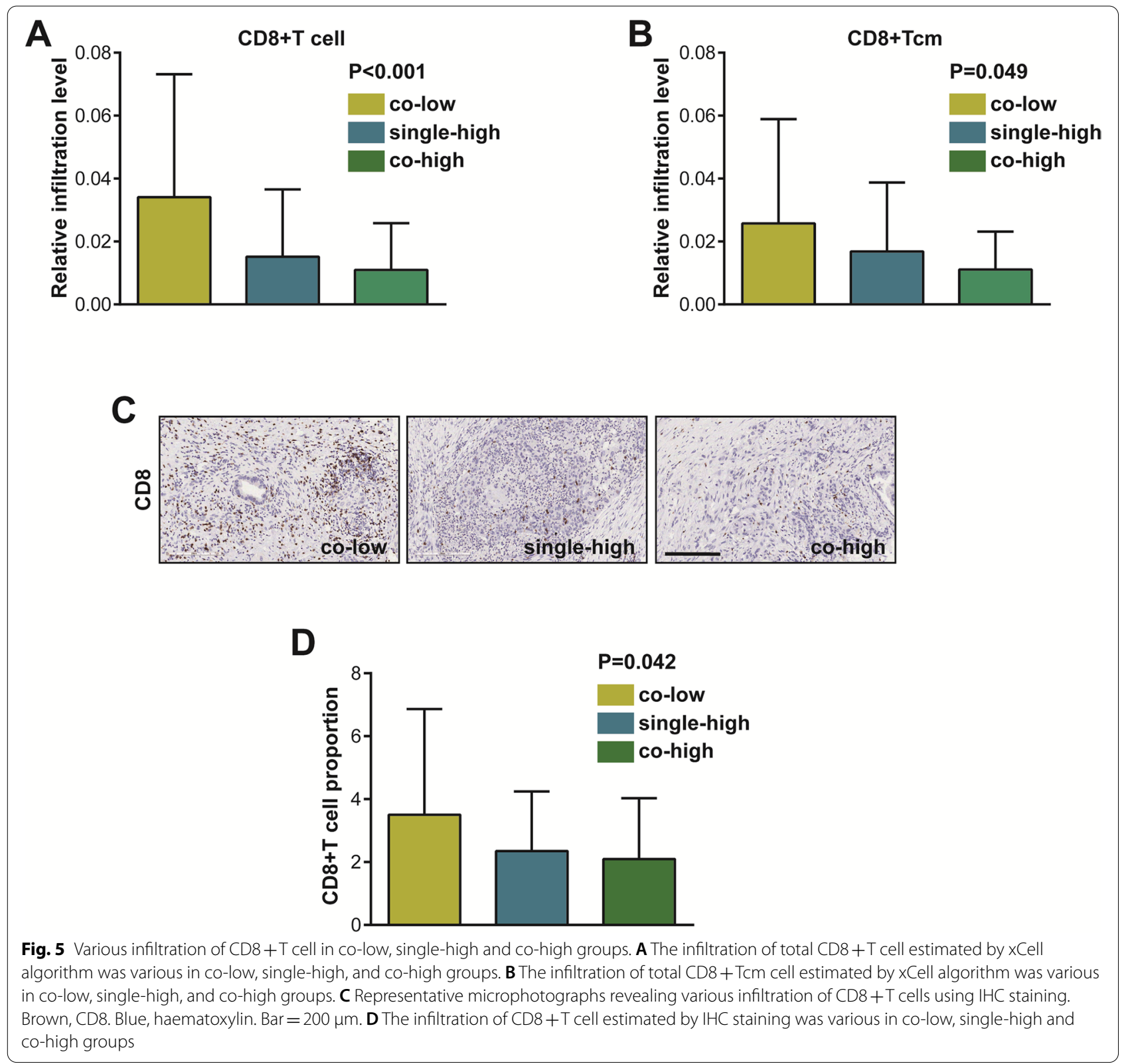

unfavorable prognostic factor for patients with PAAD [42]. In the current research, we assessed the expression of B7-H4 in tumor and para-tumor tissues in PAAD. However, the results revealed by the GEPIA and CPTAC databases showed no difference between tumor and paratumor tissues, but IHC staining uncovered that B7-H4 was significantly overexpressed in PAAD tissues. Since B7-H4 was almost only expressed in tumor cells and not in the tumor stroma, we speculated that bulk-RNA sequencing could not distinguish cell subtypes, leading to the false low expression in tumor tissues.

Interestingly, growing numbers of studies have suggested that B7 molecules exhibit limited co-expression patterns [15, 32, 43]. B7-H3 and B7-H4 exhibited no tight correlation in PAAD in our research, but no obvious pattern of mutually exclusive expression was observed as well. Novel prognostic and/or immunogenic classifiers based on different expression patterns of B7 molecules have been preliminarily investigated. For example, B7-H4 is negatively correlated with PD-L1 and identifies immuno-cold tumors in glioma [15]. In our research, we found that co-deficiency of B7-H3 and $\mathrm{B} 7-\mathrm{H} 4$ indicates better prognosis and immunohot tumors with high $\mathrm{CD} 8+\mathrm{T}$ cell infiltration, which could be applied as a novel classifier for prognostic and immunogenic assessment in PAAD. 


\section{Conclusion}

To sum up, we analyze the expression patterns and prognostic values of B7-H3 and B7-H4 in PAAD. Single B7-H3 or $\mathrm{B} 7-\mathrm{H} 4$ expression exhibits limited prognostic value for assessment of clinical outcome in PAAD, while combined their expression is a promising stratification strategy to evaluate prognosis and immunogenicity in PAAD.

\section{Abbreviations}

PAAD: Pancreatic adenocarcinoma; TME: Tumor microenvironment; TIICs: Tumor-infiltrating immune cells; PD-L1: Programmed cell death ligand 1; RNAseq: RNA-sequencing; TCGA: The Cancer Genome Atlas; TMA: Tissue microarray; IHC: Immunohistochemistry; DAB: Diaminobenzidine; OS: Overall survival; PFS: Progression-free survival; APC: Antigen-presenting cells.

\section{Supplementary Information}

The online version contains supplementary material available at https://doi. org/10.1186/s12885-022-09294-w.

Additional file 1: Figure S1. Expression levels of B7-H3 and B7-H4 PAAD tissues based on public data.

\section{Acknowledgements}

Not applicable.

\section{Authors' contributions}

Qiang Zhan conceived and designed the study. Shuping Si, Lei Wang, Hui Cao and Yuhua Xu performed the assays and bioinformatics analysis. Shuping Si prepared the figures and tables. Shuping Si and Lei Wang wrote the manuscript. Qiang Zhan revised the manuscript. All authors approved the final version of the manuscript.

\section{Funding}

This work was founded by the National Natural Science Foundation of China (No. 81773227) to Qiang Zhan and the High-end Medical Expert Team of the 2020 Taihu Talent Plan to Qiang Zhan.

\section{Availability of data and material}

All public data are available in corresponding websites and other necessary data are included in the article. In addition, the current research does not include in-house sequencing data.

\section{Declarations}

\section{Ethics approval and consent to participate}

Ethical approval for the use of the TMA was granted by the Clinical Research Ethics Committee (Outdo BioTech). Informed consent was obtained from all subjects and/or their legal guardian(s). In addition, all methods were performed in accordance with the relevant guidelines and regulations.

\section{Consent for publication}

Not applicable.

\section{Competing interests}

The authors declare no conflict of interest.

Received: 22 July 2021 Accepted: 8 February 2022

Published online: 26 February 2022

\section{References}

1. Siegel RL, Miller KD, Fuchs HE, Jemal A. Cancer Statistics, 2021. CA Cancer J Clin. 2021;71(1):7-33

2. Foley K, Kim V, Jaffee E, Zheng L. Current progress in immunotherapy for pancreatic cancer. Cancer Lett. 2016;381(1):244-51.
3. Hilmi M, Bartholin L, Neuzillet C. Immune therapies in pancreatic ductal adenocarcinoma: Where are we now? World J Gastroenterol. 2018:24(20):2137-51.

4. Banerjee K, Kumar S, Ross KA, Gautam S, Poelaert B, Nasser MW, Aithal A, Bhatia R, Wannemuehler MJ, Narasimhan B, et al. Emerging trends in the immunotherapy of pancreatic cancer. Cancer Lett. 2018;417:35-46.

5. Schizas D, Charalampakis N, Kole C, Economopoulou P, Koustas E, Gkotsis E, Ziogas D, Psyrri A, Karamouzis MV. Immunotherapy for pancreatic cancer: A 2020 update. Cancer Treat Rev. 2020;86:102016.

6. Tahkola K, Mecklin JP, Wirta EV, Ahtiainen M, Helminen O, Bohm J, Kellokumpu I. High immune cell score predicts improved survival in pancreatic cancer. Virchows Arch. 2018;472(4):653-65.

7. Stenzel PJ, Schindeldecker M, Tagscherer KE, Foersch S, Herpel E, Hohenfellner M, Hatiboglu G, Alt J, Thomas C, Haferkamp A, et al. Prognostic and Predictive Value of Tumor-infiltrating Leukocytes and of Immune Checkpoint Molecules PD1 and PDL1 in Clear Cell Renal Cell Carcinoma. Transl Oncol. 2020;13(2):336-45

8. Leung J, Suh WK. The CD28-B7 Family in Anti-Tumor Immunity: Emerging Concepts in Cancer Immunotherapy. Immune Netw. 2014;14(6):265-76.

9. Li YM, Yu JM, Liu ZY, Yang HJ, Tang J, Chen ZN. Programmed Death Ligand 1 Indicates Pre-Existing Adaptive Immune Response by Tumor-Infiltrating CD8(+)T Cells in Non-Small Cell Lung Cancer. Int J Mol Sci. 2019;20(20):5138.

10. Wei XL, Liu QW, Liu FR, Yuan SS, Li XF, Li JN, Yang AL, Ling YH. The clinicopathological significance and predictive value for immunotherapy of programmed death ligand-1 expression in Epstein-Barr virus-associated gastric cancer. Oncoimmunology. 2021;10(1):1938381.

11. Ni L, Dong C. New B7 Family Checkpoints in Human Cancers. Mol Cancer Ther. 2017;16(7):1203-11.

12. Yamato I, Sho M, Nomi T, Akahori T, Shimada K, Hotta K, Kanehiro H, Konishi N, Yagita H, Nakajima Y. Clinical importance of B7-H3 expression in human pancreatic cancer. Br J Cancer. 2009:101(10):1709-16.

13. Shen L, Qian Y, Wu W, Weng T, Wang FXC, Hong B, Wu Z, Wang Q, Sang $\mathrm{Y}$, Zhang $\mathrm{H}$, et al. B7-H4 is a prognostic biomarker for poor survival in patients with pancreatic cancer. Hum Pathol. 2017;66:79-85.

14. Cherif B, Triki H, Charfi S, Bouzidi L, Kridis WB, Khanfir A, Chaabane K, Sellami-Boudawara T, Rebai A. Immune checkpoint molecules B7-H6 and PD-L1 co-pattern the tumor inflammatory microenvironment in human breast cancer. Sci Rep. 2021:11(1):7550.

15. Chen D, Li G, Ji C, Lu Q, Qi Y, Tang C, Xiong J, Hu J, Yasar FBA, Zhang Y, et al. Enhanced B7-H4 expression in gliomas with low PD-L1 expression identifies super-cold tumors. J Immunother Cancer. 2020;8(1):e000154.

16. Tang Z, Li C, Kang B, Gao G, Li C, Zhang Z. GEPIA: a web server for cancer and normal gene expression profiling and interactive analyses. Nucleic Acids Res. 2017;45(W1):W98-102.

17. Chen F, Chandrashekar DS, Varambally S, Creighton CJ. Pan-cancer molecular subtypes revealed by mass-spectrometry-based proteomic characterization of more than 500 human cancers. Nat Commun. 2019;10(1):5679.

18. Li T, Fan J, Wang B, Traugh N, Chen Q, Liu JS, Li B, Liu XS. TIMER: A Web Server for Comprehensive Analysis of Tumor-Infiltrating Immune Cells. Cancer Res. 2017;77(21):e108-10.

19. Aran $\mathrm{D}, \mathrm{Hu} Z$, Butte AJ. xCell: digitally portraying the tissue cellular heterogeneity landscape. Genome Biol. 2017;18(1):220.

20. Cai Y, Ji W, Sun C, Xu R, Chen X, Deng Y, Pan J, Yang J, Zhu H, Mei J. Interferon-Induced Transmembrane Protein 3 Shapes an Inflamed Tumor Microenvironment and Identifies Immuno-Hot Tumors. Front Immunol. 2021;12(3162):704965.

21. Liu S, Liang J, Liu Z, Zhang C, Wang Y, Watson AH, Zhou C, Zhang F, Wu K, Zhang F, et al. The role of CD276 in Cancers. Front Oncol. 2021;11:654684.

22. Wang JY, Wang WP. B7-H4, a promising target for immunotherapy. Cell Immunol. 2020;347:104008.

23. Fauci JM, Straughn JM Jr, Ferrone S, Buchsbaum DJ. A review of B7-H3 and $\mathrm{B} 7-\mathrm{H} 4$ immune molecules and their role in ovarian cancer. Gynecol Oncol. 2012;127(2):420-5

24. Kim NI, Park MH, Kweon SS, Lee JS. B7-H3 and B7-H4 expression in breast cancer and their association with clinicopathological variables and T Cell infiltration. Pathobiology. 2020:87(3):179-92.

25. Craig SG, Humphries MP, Alderdice M, Bingham V, Richman SD, Loughrey MB, Coleman HG, Viratham-Pulsawatdi A, McCombe K, Murray $\mathrm{Gl}$, et al. Immune status is prognostic for poor survival in colorectal cancer patients and is associated with tumour hypoxia. Br J Cancer. 2020;123(8):1280-8. 
26. Ren F, Zhao Q, Minghai Z, Shaogong Z, Liu B, Bukhari I, Zhang K, Wu W, Yuming F, Yu Y, et al. Immune infiltration profiling in gastric cancer and their clinical implications. Cancer Sci. 2021;112(9):3569-84.

27. Hu R, Han Q, Zhang J. STAT3: A key signaling molecule for converting cold to hot tumors. Cancer Lett. 2020;489:29-40.

28. Suh WK, Gajewska BU, Okada H, Gronski MA, Bertram EM, Dawicki W, Duncan GS, Bukczynski J, Plyte S, Elia A, et al. The B7 family member B7-H3 preferentially down-regulates $T$ helper type 1-mediated immune responses. Nat Immunol. 2003:4(9):899-906.

29. Nunes-Xavier CE, Kildal W, Kleppe A, Danielsen HE, Waehre H, Llarena R, Maelandsmo GM, Fodstad O, Pulido R, Lopez JI. Immune checkpoint B7$\mathrm{H} 3$ protein expression is associated with poor outcome and androgen receptor status in prostate cancer. Prostate. 2021;81(12):838-48.

30. Koyama Y, Morikawa T, Miyama Y, Miyakawa J, Kawai T, Kume H, Sawabe M, Ushiku T. B7-H3 expression in upper tract urothelial carcinoma associates with adverse clinicopathological features and poor survival. Pathol Res Pract. 2020;216(12):153219.

31. Qiu MJ, Xia Q, Chen YB, Fang XF, Li QT, Zhu LS, Jiang X, Xiong ZF, Yang SL. The expression of three negative Co-Stimulatory B7 family molecules in small cell lung cancer and their effect on prognosis. Front Oncol. 2021;11:600238

32. Carvajal-Hausdorf D, Altan M, Velcheti V, Gettinger SN, Herbst RS, Rimm DL, Schalper KA. Expression and clinical significance of PD-L1, B7-H3, B7-H4 and TILs in human small cell lung Cancer (SCLC). J Immunother Cancer. 2019;7(1):65.

33. Yim J, Koh J, Kim S, Song SG, Ahn HK, Kim YA, Jeon YK, Chung DH. Effects of B7-H3 expression on tumour-infiltrating immune cells and clinicopathological characteristics in non-small-cell lung cancer. Eur J Cancer. 2020;133:74-85.

34. Zhao X, Li DC, Zhu XG, Gan WJ, Li Z, Xiong F, Zhang ZX, Zhang GB, Zhang $X G$, Zhao H. B7-H3 overexpression in pancreatic cancer promotes tumor progression. Int J Mol Med. 2013;31 (2):283-91.

35 Inamura K, Takazawa Y, Inoue Y, Yokouchi Y, Kobayashi M, Saiura A Shibutani T, Ishikawa Y. Tumor B7-H3 (CD276) Expression and Survival in Pancreatic Cancer. J Clin Med. 2018;7(7):172.

36. Niu N, Shen W, Zhong Y, Bast RC Jr, Jazaeri A, Sood AK, Liu J. Expression of $\mathrm{B} 7-\mathrm{H} 4$ and IDO1 is associated with drug resistance and poor prognosis in high-grade serous ovarian carcinomas. Hum Pathol. 2021;113:20-7.

37. Mizuno T, Kamai T, Tsuzuki T, Nishihara D, Kijima T, Arai K, Yoshida $\mathrm{KI}$. Elevated expression of B7 homolog 4 is associated with disease progression in upper urinary tract urothelial carcinoma. Cancer Immunol Immunother. 2021;2022(3):565-78. https://doi.org/10.1007/ s00262-021-03011-5.

38. Ding S, Lv X, Liu Z, Zhan S, Xu Y, Zhang X, Liu C, Cao L. Overexpression of B7-H4 is associated with infiltrating immune cells and poor prognosis in metastatic colorectal cancer. Int Immunopharmacol. 2021;90:107144.

39. Song X, Zhou Z, Li H, Xue Y, Lu X, Bahar I, Kepp O, Hung MC, Kroemer G, Wan Y. Pharmacologic Suppression of B7-H4 Glycosylation Restores Antitumor Immunity in Immune-Cold Breast Cancers. Cancer Discov. 2020;10(12):1872-93.

40. Pagnotti GM, Atkinson RM, Romeiser J, Akalin A, Korman MB, Shroyer KR. B7-H4 is Inversely Correlated With T-Cell Infiltration in Clear Cell but Not Serous or Endometrioid Ovarian Cancer. Appl Immunohistochem Mol Morphol. 2019;27(7):515-22.

41. Qian Y, Hong B, Shen L, Wu Z, Yao H, Zhang L. B7-H4 enhances oncogenicity and inhibits apoptosis in pancreatic cancer cells. Cell Tissue Res. 2013;353(1):139-51.

42. Chen X, Tao L, Yuan C, Xiu D. The prognostic value of B7-H4 in pancreatic cancer: Systematic review and meta-analysis. Medicine (Baltimore). 2018;97(12):e0088.

43. Altan M, Pelekanou V, Schalper KA, Toki M, Gaule P, Syrigos K, Herbst RS, Rimm DL. B7-H3 Expression in NSCLC and Its Association with B7-H4, PD-L1 and Tumor-Infiltrating Lymphocytes. Clin Cancer Res. 2017;23(17):5202-9.

\section{Publisher's Note}

Springer Nature remains neutral with regard to jurisdictional claims in published maps and institutional affiliations.

Ready to submit your research? Choose BMC and benefit from:

- fast, convenient online submission

- thorough peer review by experienced researchers in your field

- rapid publication on acceptance

- support for research data, including large and complex data types

- gold Open Access which fosters wider collaboration and increased citations

- maximum visibility for your research: over $100 \mathrm{M}$ website views per year

At BMC, research is always in progress.

Learn more biomedcentral.com/submissions 